\title{
Modernized Forest Fire Risk Assessment Model Based on the Case Study of three Portuguese Municipalities Frequently Affected by Forest Fires ${ }^{\dagger}$
}

\author{
Luis Santos ${ }^{1,2, *}$, Vasco Lopes ${ }^{1}$ and Cecília Baptista ${ }^{1,3}$ \\ 1 Polytechnic Institute of Tomar, School of Technology, 2300-313 Tomar, Portugal; \\ vaalopes19@gmail.com (V.L.); cecilia@ipt.pt (C.B.) \\ 2 Geosciences Research Center, Coimbra University, 3030-790 Coimbra, Portugal \\ 3 Centre for Technology, Restoration and Art Enhancement (Techn\&Art), 2300-313 Tomar, Portugal \\ * Correspondence: 1santos@ipt.pt; Tel.: +351-967743365 \\ + Presented at the 1st International Electronic Conference on Forests - Forests for a Better Future: Sustainability, \\ Innovation, Interdisciplinarity, 15-30 November 2020; Available online: https://iecf2020.sciforum.net.
}

Citation: Santos, L.; Lopes, V.; Baptista, C. Modernized Forest Fire Risk Assessment Model Based on the Case Study of three Portuguese Municipalities Frequently Affected by Forest Fires. Environ. Sci. Proc. 2021, 3, 30. https://doi.org/ 10.3390/IECF2020-07973

Academic Editors: Angela Lo Monaco, Cate Macinnis-Ng and Om P. Rajora

Published: 12 November 2020

Publisher's Note: MDPI stays neutral with regard to jurisdictional claims in published maps and institutional affiliations.

\section{Copyright: $\odot 2020$ by the authors.} Licensee MDPI, Basel, Switzerland. This article is an open access article distributed under the terms and conditions of the Creative Commons Attribution (CC BY) license (http://creativecommons.org/licenses/by/4.0/).

\begin{abstract}
The number of forest fires ignitions has decreased worldwide, thus observing increased levels of intensity and destruction, endangering urban areas and causing material damages and deaths (Portugal, 2017). Forest fire hazard mapping supported by the surveillance strategy targeted at very susceptible areas with high losses potential are the common tools of fire prevention. Each municipality creates its own Forest Fire Hazard Map, and so it is observed that along the administrative boundaries, discrepancies occur, even when identical types of land use are in place. The evolution of geographic information systems technology sustained by the open-source satellite imagery, along with the innovative Habitat Risk Assessment model of the InVEST software, allowed the creation of an easily applicable trans-administrative boundary fire hazard map, with frequent update capabilities and fully open source. This work considered three municipalities (Tomar, Ourém, and Ferreira do Zêzere) that annually observe various forest fire occurrences. Results enabled the creation of a homogeneous Forest Fire Risk Map, using landuse, slope, road access network, fire ignitions' history, visualization basins, and the Normalized Difference Vegetation Index (NDVI) as variables. All variables correlate with each other using different weights, in which the different classes of land use are considered as habitats and the remaining variables as fire hazard stressors. The results produce a coherent monthly updated Risk Map, which is an alternative to many risk assessment systems used worldwide.
\end{abstract}

Keywords: fire hazard; InVEST; NDVI; model; forest fires

\section{Introduction}

Wildfires arise naturally from sources such as spontaneous combustion of dry matter, under high temperatures and wind conditions, or most commonly lightning strikes [1]. Most frequently, wildfire ignitions arise as accidental consequences of human practices, though many have been proven to be criminal or negligent actions [2,3].

Mediterranean forests are regularly subjected to a large number of fires [4-6], changes in land use patterns [7], and the impacts of socio-economic factors on land management practices [8], further aggravated by major modifications to forest ecosystems during the second half of the 20th century [9] along with forest modification by fire recurrence [10] contributed towards wildfire intensification.

With farmland abandonment and forest modification trends, fire concentration is becoming rather predominant in Southern European regions [4]. In the past years (20182019), fires in Europe observed over 800,000 hectares of burnt areas in Portugal, Italy, and 
Spain alone [11]. The number of occurrences regarding forest fires has decreased worldwide [12], thus observing increased levels of intensity and destruction, which in many cases endanger urban areas, causing not only material damage but also deaths, such as those that occurred in Portugal in 2017 [9]. Wildfires, and in particular forest fires, are increasing in intensity, reaching catastrophic dimensions, as a result of poor forest management, territorial planning, and economic pressures, also driven by aggravated climate change conditions $[7,10,13]$.

Surely fire represents an important ecological function and a strategic agricultural tool to fertilize soils [14,15]; however, the fire-fighting associated costs, the human lives [16], the property and natural resources lost [11], the environmental greenhouse gas emissions and atmospheric pollution factors [17], and the ecosystem services lost [15] represent heavy counter-weights of sustainability scales.

Wildfires can be termed as forest fires, grass fires, peat fires, and bush fires, depending on the predominant type of vegetation that is being burnt. Forest fires in Portugal, as in the Mediterranean region, can occur at any given time; however, they are more prevalent during the dry season between the beginning of summer and the start of the winter rains $[4,18]$. Climate change effects, increasing drought frequency, and associated average temperature rise, when combined with population density and economic activity, which increase the urban forest interface, will further increase wildfire frequency and severity $[8,9]$. All catastrophic fires in Portugal occur within the summer period, when the association of three variables, heat, wind, and lack of humidity, align with the 30 's rule: over $30 \mathrm{~km} / \mathrm{h}$ winds, over $30^{\circ}$ Celsius, and less than $30 \%$ humidity.

The evolution of geographic information systems (GIS) with a panoply of software and applications, both commercial and open source, enables easy fire-risk cartography, which requires a dynamic process, since a certain location in a given time quickly changes either by seasonal changes, land occupation, or land use, thus providing a fundamental tool in support of forest fire prevention, surveillance, and mitigation $[19,20]$. Wildfire mitigation analysis evolved considerably since the turn of the century: satellite imagery and remote sensing (RS) analysis are now widely used to detect and monitor the behavior of, and aid operational fire-fighting activities, and facilitate the mapping of burned areas. These technologies are proven to be more efficient and precise than traditional surveying methods, reducing risk and burnt areas and saving human lives [20].

By using models, maps, and databases in geospatial analysis of fire variables, every country prone to wildfires produces risk maps as a strategy to optimize monitoring and minimize losses during the seasonal fire-fighting season. Risk mapping focuses on lowprobability, high-consequence adverse events that are stochastic in space. As an operational result, countries allocate watchtowers, open forest accessibility facilities, distribute facilities, and surveying mobile teams in risky areas [16].

The Portuguese municipality risk map (PMDFCI) production guidelines proposed by the governmental Institute for Nature Conservation and forestry (ICNF) contemplates Hazard as a multiplication product of probability and susceptibility and potential losses as a multiplicative product of vulnerability and economic value, where risk is the multiplicative result of hazard and potential damage (Figure 1). 


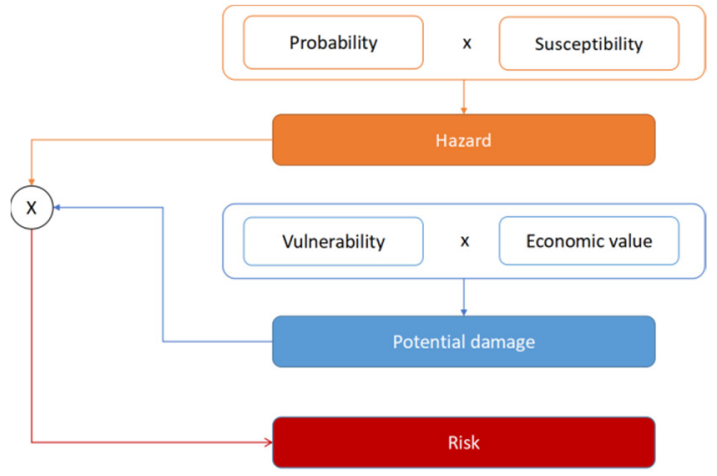

Figure 1. PMDFCI production instructions (Source ICNF).

The probability criterion considers fire history as the product of occurrences multiplied by 100, divided by the number of series (years), whereas susceptibility considers land-cover in eight categories with forest and brush with higher susceptibility and slope, where steeper slopes are considered most susceptible. The vulnerability criterion is applied to combustion resilience of materials and economic market value of goods.

Some of the underlying problems observed with PMDFCI methodology concern the individually implemented municipality base risk maps which create hard boundaries where the same habitat across two municipalities observes a different risk class. Furthermore, the model is mostly produced with static characteristics where slow update variables are used (Figure 2).

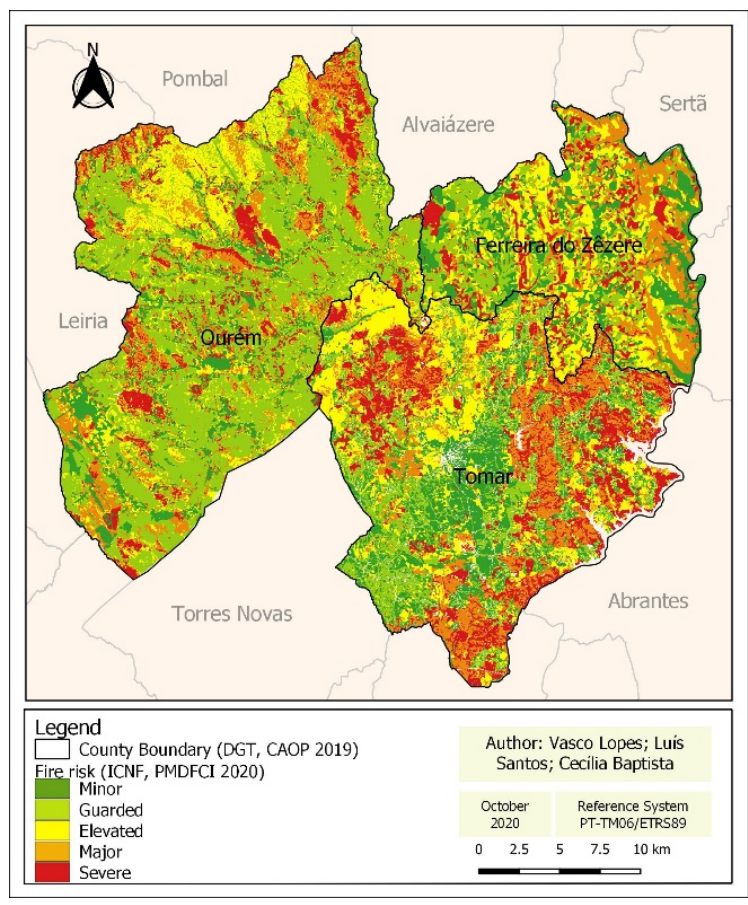

(a)

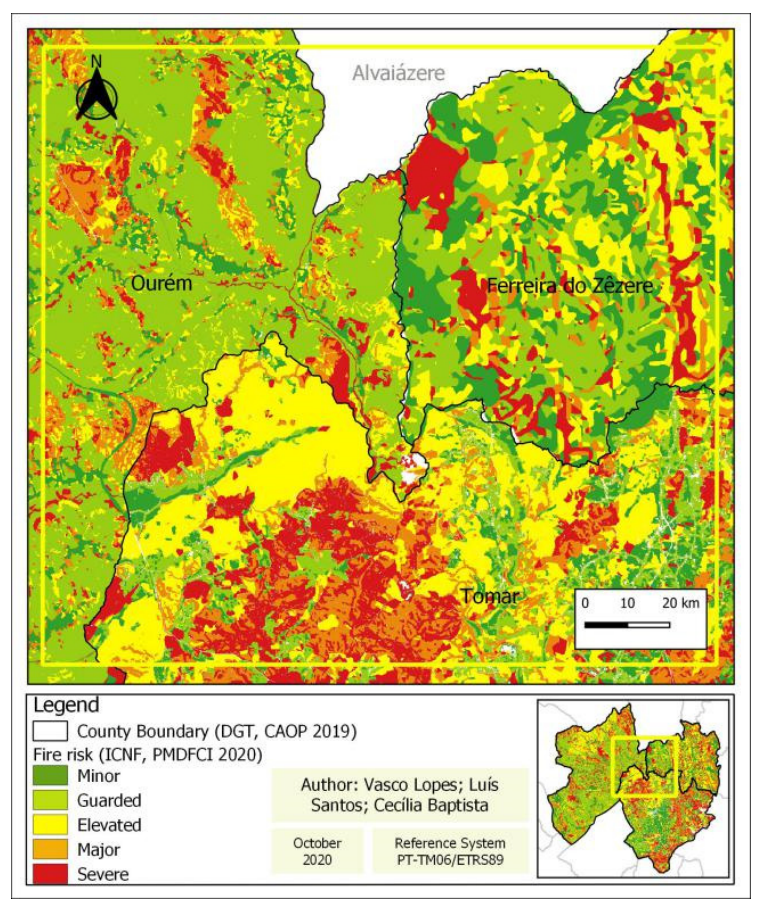

(b)

Figure 2. (a) PMDFCI risk model for the study region, (b) PMDFCI Risk detail of municipality boundaries.

The objective of this paper is to produce an open source, updatable and upgradable, transboundary base solution of forest fire ignition risk mapping and use it for identifying locations, determined from a set of slow and dynamic variables, thus mitigating susceptibility and social/infrastructural vulnerability. 


\section{Materials and Methods}

With the evolution of geographic information technology and the multitude of free satellite imagery, the methodology used in the Habitat Risk Assessment model, one of the InVEST (Integrated Valuation of Ecosystem Services and Tradeoffs) models used to map and value the goods and services from nature that sustain and fulfil human life. The InVEST Habitat and Species Risk Assessment (HRA) model allows the assessment of cumulative risk posed to habitats by human activities, delivering ecosystem risk map, risk maps for each individual habitat, resulting from the contribution of exposure and consequence to overall risk [21].

This work enabled the creation of a homogeneous Fire Ignition Risk map, which used as variables land occupation, slope, forest road network, history of fire ignitions, visualization basins, and the Normalized Difference Vegetation Index (NDVI). All variables correlated with each other using different weights, in which the different classes of land occupation enter as habitats and the remaining as stressors for the problem of fires.

\subsection{Study Area}

The study region located in the center of Portugal covering the transition between the Tagus river floodplains and the Montejunto-Estrela mountain range (Central Portugal; Figure 3). Administratively, the region comprises the municipalities of Tomar, Ourém, and Ferreira do Zêzere belonging to Santarém district, Nomenclature of Territorial Units for Statistical Purposes (NUTS) level II and III; the municipalities are inserted in the Central region and in the sub-region of the Middle Tagus. They are situated in the Mediterranean pluvioseasonal oceanic bio-climatic region [22] with average altitude ranging from 30 to $650 \mathrm{~m} \mathrm{~s}$ a l., mean annual precipitation of $66 \mathrm{~mm}$, and a mean annual temperature of $14{ }^{\circ} \mathrm{C}$. This region observes on average $2-3$ months of summer drought when wildfires are frequent, particularly because of the association with poor management, land abandonment as a consequence of ageing population and desertification, and the choice of species influenced by economic yields.

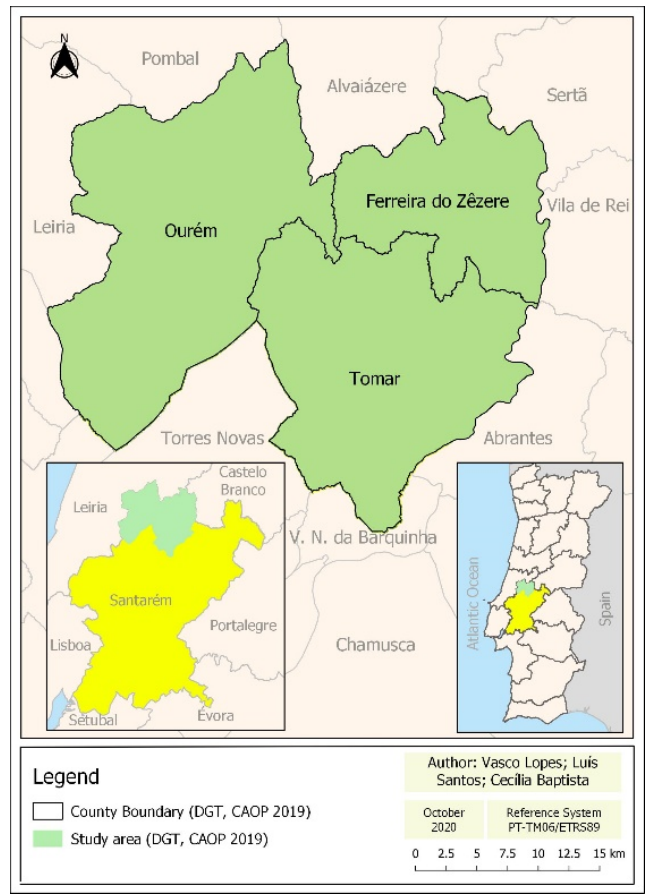

Figure 3. Geographical location of study region. 
The region was once prosperous with Pinus pinaster plantations speckled with olive orchards and lowland agriculture; nowadays it is a mosaic of Eucalyptus globulus plantations, remnants of Pinus pinaster, and shrubland dominated by Ulex spp., Erica spp., Pistacea sp., Myrtus sp., and Rubus spp., where once was agriculture, confirming a trend that is further observed as we move north-eastwards. According to the data of the Official Administrative Chart of Portugal (DGT-2019), the three municipalities cover an area of approximately 95,823 ha, divided as follows: Tomar (35,120 ha), Ourém (41,666 ha), and Ferreira do Zêzere (19,037 ha).

\subsection{Methods}

The methodology applied for the current study used imagery from the satellite constellation Sentinel-2 multispectral instrument (MSI), which offered the possibility of obtaining information in medium and high spatial resolution $(10-20 \mathrm{~m})$. In particular, the MSI sensor provides spectral information in different bands, allowing for the calculation of pre-fire vegetation greenness, the normalized difference vegetation index (NDVI, Theorem 1). For greenness chlorophyll concentration NDVI, we used Red and NIR according to the formula described on Theorem 1.

$$
N D V I=\frac{N I R-R e d}{N I R+R e d}
$$

Theorem 1. Normalized difference vegetation index (NDVI), red region (Red: 650-680 nm, $10 \mathrm{~m}$ resolution) being the near infrared (NIR: 785-899 nm, $10 \mathrm{~m}$ resolution).

The downloaded images for the study region, level 2A, atmospherically, radiometrically, and geometrically corrected, from the July 24 to August 23, 2019, without the presence of clouds, where the final data was selected for values up to 0.4 , considering loss of chlorophyll as the dynamic variable with monthly images frequency $[20,23,24]$.

The Modernized Dynamic Ignition Risk (MDIR) model (Figure 4) considers ignition risk as the trigger to fire occurrence, both large and small; this factor conveys a safer approach to monitoring and mitigation actions of firefighting agents. The slow geodatabase variables used were land-cover with forest and brush representing higher risk and anthropic territories such as cities lower from National Landcover Maps Level 1 (COS). Road network selected $20 \mathrm{~m}$ high risk, considering most ignitions start within the proximity of roads, thus emphasizing the criminal and accidental majority of ignitions from the National Institute for Nature conservation and forestry (ICNF) [25]. The history of fire ignitions, considering that a burnt area will, according to natural regeneration, have some years before recurrent ignition, means that ecological succession will represent higher risk. Data used are from 2011-2019 from the National Service for Nature and Environment Protection (SEPNA). Population density (people per sq. $\mathrm{km}$ ) is according to census 2011, where areas bellow 250 residents increase the risk, desertification, and aged population, from the National Statistics Institute (INE). As low slopes are considered prone areas for ignition, this may cause confusion, as high slopes are favorable to fire propagation; however, ignition data from the past nine years reveals that the majority of ignitions occur in lower slope areas; slope was calculated with QGIS from DTM 25 m resolution. Visualization through the construction of watchtowers is one of the monitoring strategies implemented worldwide; for this study, all areas not visible by at least three towers are considered of high risk; visualization was calculated using the watchtower locations, in turn applying viewshed analysis QGIS plug-in (SEPNA).

The MDIR model adopts free open source software QGIS and GRASS to prepare all vector and raster inputs for the InVEST HRA, applying Landcover as the current habitat split into individual categories, with slope, visibility, roads, fire ignition history, and population density as stressors. Requiring a classification criteria table, HRA, classifies each variable as exposure or consequence; the habitats will be rated for growth rate, rotation, 
connectivity, and natural recovery time based on literature information, evaluating data quality and weight. For each stressor, ratings were considered for distribution frequency, change in classification, management efficiency, and neighborhood, also evaluating data quality and weight.

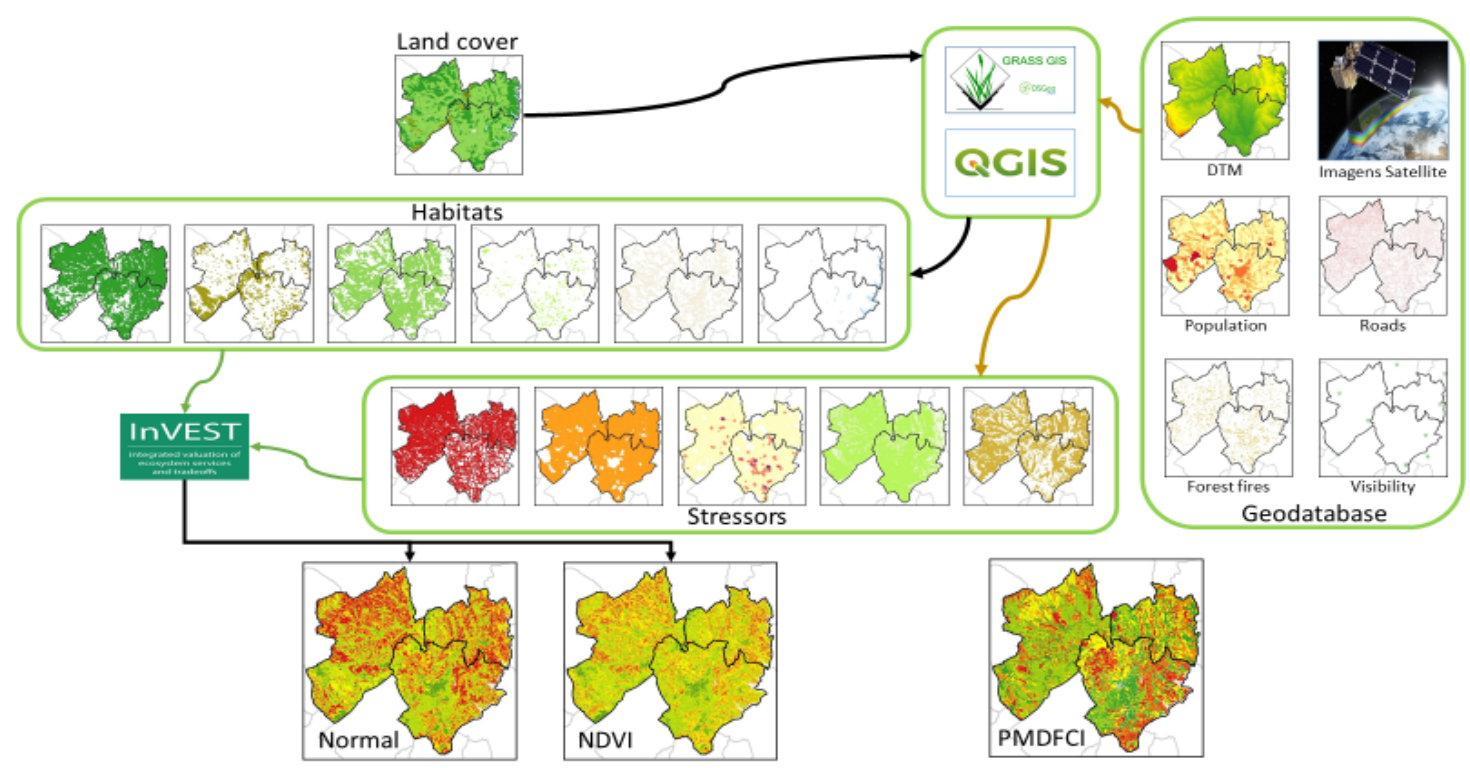

Figure 4. Modernized Dynamic Ignition Risk model (MDIR), elaboration process.

The InVEST HRA model cumulatively analyses habitat characteristics as mitigation factors and stressors as deteriorating factor of risk producing risk maps for the study region.

\section{Results and Discussion}

Results delivered as risk maps from the HRA for the study region were tested using the different sets of stressors to understand the differences between slow and dynamic variables. As a first run of the HRA, only slow variables were analyzed and risk classes were attributed as Minor, Guarded, Elevated, and Severe, using designated Modernized Ignition Risk (MIR) (Figure 5a). Classification considers risk is always present except for water surfaces, and therefore no risk classification was not used in the risk map.

Results generated from the InVEST HRA in the production of the MIR map (Figure 5a) are considerably different from the PMDFCI; when we focus on municipal boundaries, a soft transboundary risk classification can be observed (Figure $5 b$ ).

The inclusion of the dynamic (monthly) greenness (NDVI) stress, denominated Modernized Dynamic Ignition Risk model (MDIR), delivers a substantially different ignition risk map (Figure 6a,b). 


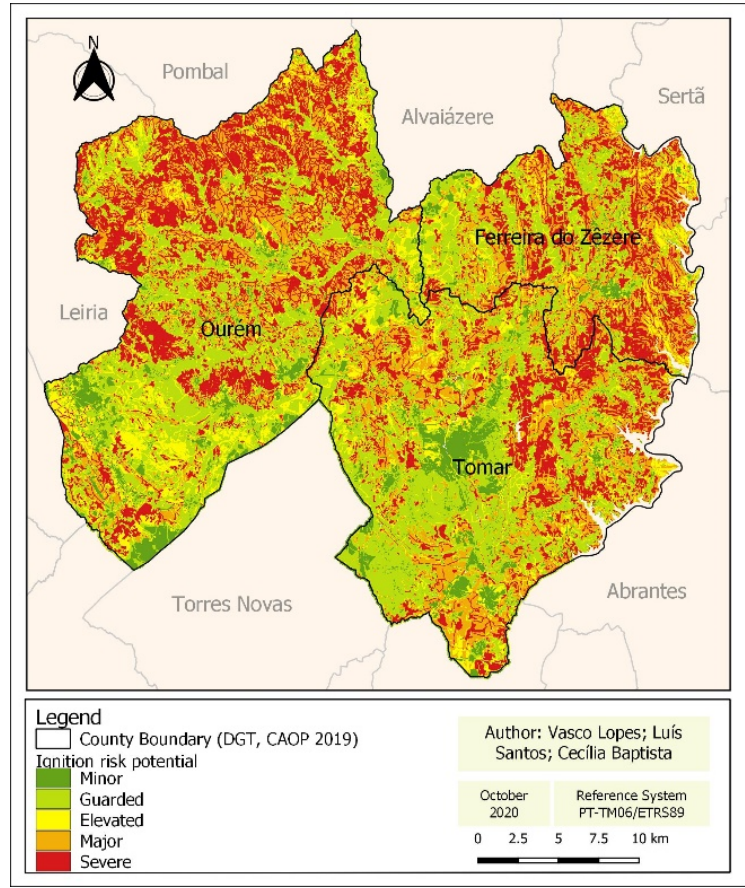

(a)

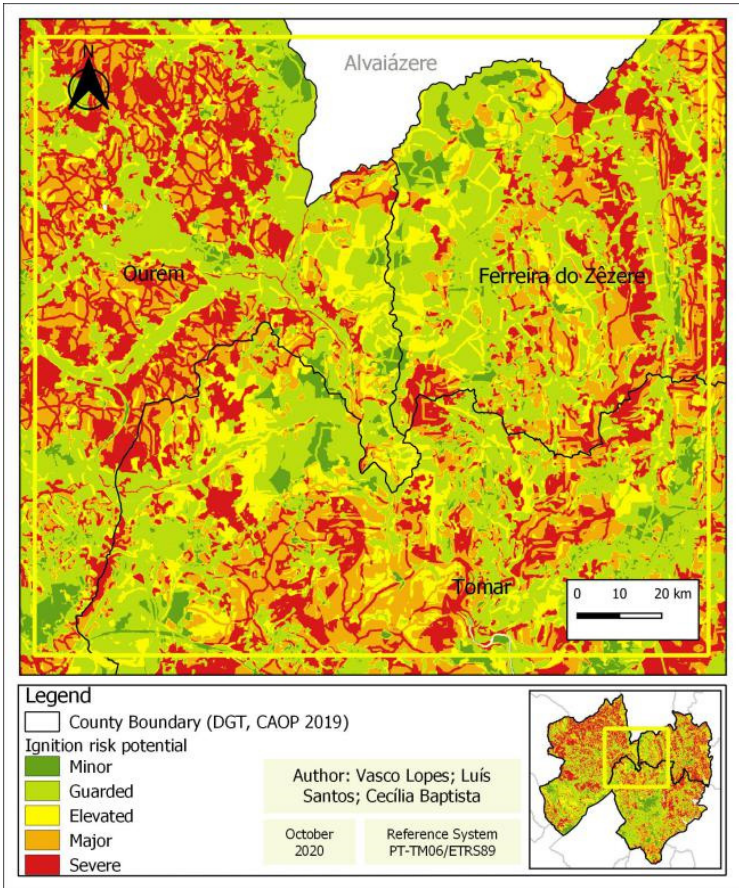

(b)

Figure 5. Ignition Risk Model (MIR) map considering slow variables (a) MIR for the entire region, (b) MIR detail of inter municipality boundaries.

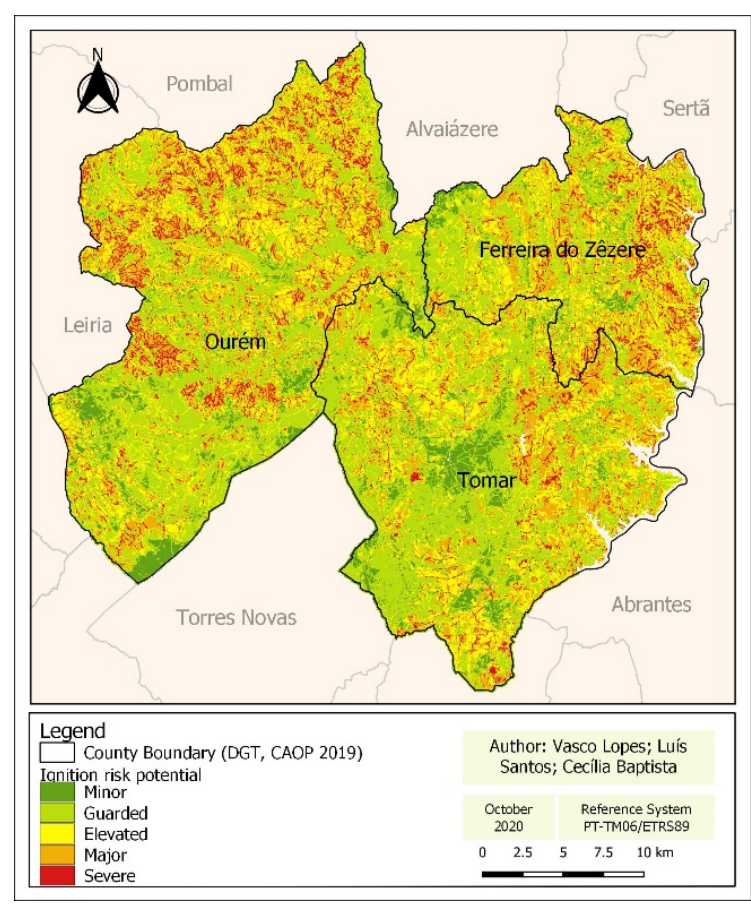

(a)

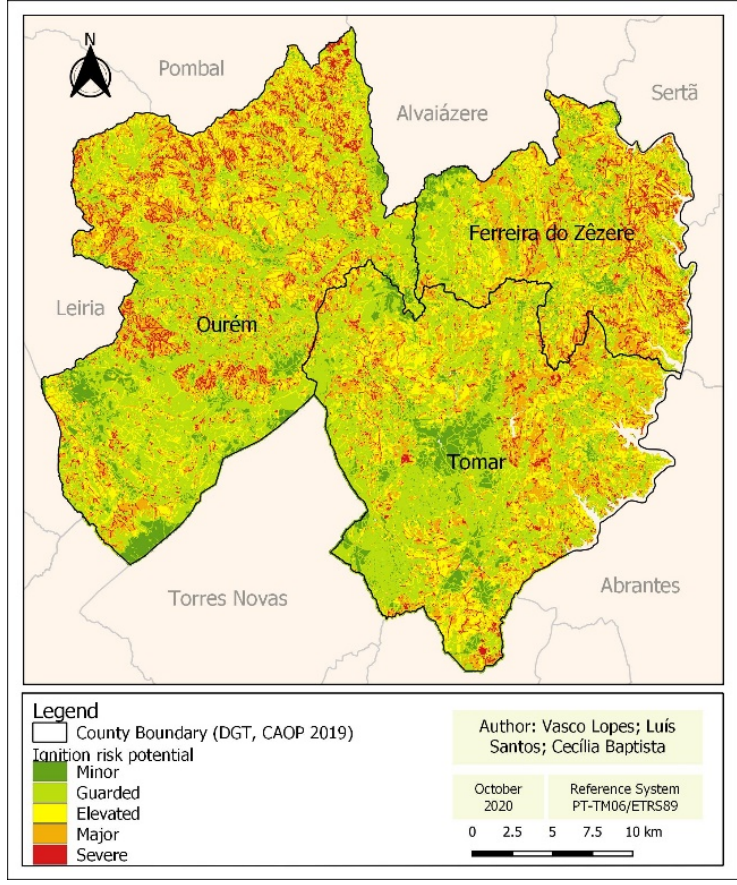

(b)

Figure 6. Ignition risk map with slow variables using dynamic NDVI as a stressor, (a) NDVI-July 24, 2019, (b) NDVIAugust 23, 2019.

When comparing MIR and MDIR model results with the PMDFCI, the $10 \%$ increase of severe risk class in MIR and the 7\% decrease in MDIR (Figure 7a) are clearly visible; the former is based on slow variables, and one can just attribute the latter reduction to the dynamic NDVI stress, which repercusses the climatic influence, thus pinpointing severe 
risk areas. This fact may reveal to be an interesting cue to monitoring and surveying strategies.

On the other hand, lower classifications, minor and guarded, when added, are $49 \%$ for PMDFCI, $48 \%$ for MDIR, and $41 \%$ for MIR. The close percentage observed between PMDFCI and MDIR indicates that natural conditions are equally considered in both models, further evidenced in the geographical span; however, MDIR may, due to its dynamic nature (monthly), express climate change conditions, whereas PMDFCI is static.

Figure $7 \mathrm{~b}$ compares MDIR results between July 24 and the August 23, 2019, where there is a slight risk increase $(0.1 \%)$, except for the minor risk class that decreased $0.5 \%$; values may seem residual; however, chlorophyll loss in some well adapted plants is not a rapid process.

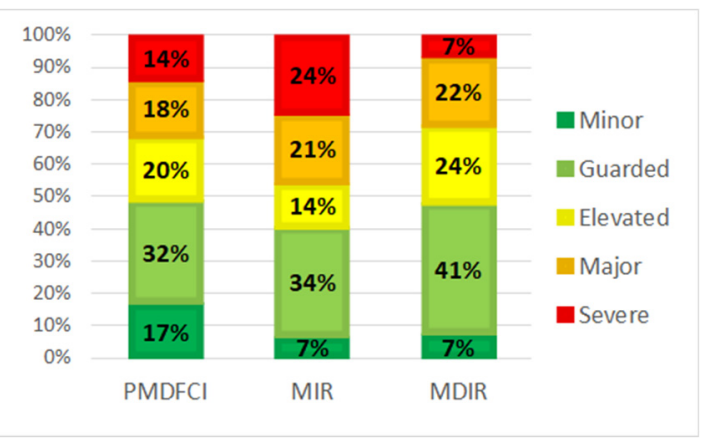

(a)

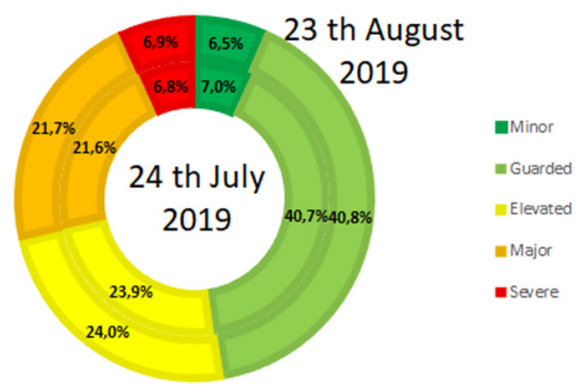

(b)

Figure 7. (a) Comparison bar chart between the two variations of the modernized model and PMDFCI, (b) Comparison pie chart between the MDIR of July 24 and August 23, 2019.

Model functional practicability is probably the most important characteristic of predicted results, hence the need to further exploit stressors and mitigation variables to optimize MDIR.

\section{Conclusions}

The integrated analysis of spatial slow and dynamic variables enabled by the InVest HRA model are valuable resources for forest fire research, and when fused with remote sensing satellite imagery combined with GIS processing, made possible the creation of fire ignition models MIR and MDIR. The produced models used literature proven valid variables and performed properly in identifying areas of high ignition risk.

The MIR model offers a generic well-defined severe risk area and may be useful as a general-purpose ignition risk map, whereas the MDIR offers a possible solution for monitoring and surveillance, despite the needed research and validation. MDIR model offers a solution that using NDVI indirectly includes the climate change, though being the only dynamic variable would benefit from short wave infrared, Normalized Distance Water Index (NDWI).

Although much research is needed, the proposed models are fully updatable and built entirely with open source software and hence are accessible to anyone.

Data Availability Statement: All data used in the current study is under access via public Internet and GEANT network, with committed reliability and performance on https://sentinels.copernicus.eu/web/sentinel/home.

\section{References}

1. Couto, F.T.; Iakunin, M.; Salgado, R.; Pinto, P.; Viegas, T.; Pinty, J.P. Lightning modelling for the research of forest fire ignition in Portugal. Atmos. Res. 2020, 242, 104993.

2. Kountouris, Y. Human activity, daylight saving time and wildfire occurrence. Sci. Total Environ. 2020, 727, 138044.

3. Balch, J.K.; Bradley, B.A.; Abatzoglou, J.T.; Nagy, R.C.; Fusco, E.J.; Mahood, A.L. Human-started wildfires expand the fire niche across the United States. Proc. Natl. Acad. Sci. USA 2017, 114, 2946-2951. 
4. García-Llamas, P.; Suárez-Seoane, S.; Taboada, A.; Fernández-Manso, A.; Quintano, C.; Fernández-García, V.; FernándezGuisuraga, J.M.; Marcos, E.; Calvo, L. Environmental drivers of fire severity in extreme fire events that affect Mediterranean pine forest ecosystems. For. Ecol. Manag. 2019, 433, 24-32.

5. Oliveira, S.; Oehler, F.; San-Miguel-Ayanz, J.; Camia, A.; Pereira, J.M.C. Modeling spatial patterns of fire occurrence in Mediterranean Europe using Multiple Regression and Random Forest. For. Ecol. Manag. 2012, 275, 117-129.

6. Quintano, C.; Fernández-Manso, A.; Stein, A.; Bijker, W. Estimation of area burned by forest fires in Mediterranean countries: A remote sensing data mining perspective. For. Ecol. Manag. 2011, 262, 1597-1607.

7. Fernandes, P.M. Fire-smart management of forest landscapes in the Mediterranean basin under global change. Landsc. Urban Plan. 2013, 110, 175-182.

8. Galizia, L.F.D.; Rodrigues, M. Modeling the influence of eucalypt plantation on wildfire occurrence in the Brazilian savanna biome. Forests 2019, 10, 844 .

9. Navalho, I.; Alegria, C.; Quinta-Nova, L.; Fernandez, P. Integrated planning for landscape diversity enhancement, fire hazard mitigation and forest production regulation: A case study in central Portugal. Land Use Policy 2017, 61, $398-412$.

10. Puerta-Piñero, C.; Espelta, J.M.; Sánchez-Humanes, B.; Rodrigo, A.; Coll, L.; Brotons, L. History matters: Previous land use changes determine post-fire vegetation recovery in forested Mediterranean landscapes. For. Ecol. Manag. 2012, 279, 121-127.

11. Alló, M.; Loureiro, M.L. Assessing preferences for wildfire prevention policies in Spain. For. Policy Econ. 2020, $115,102145$.

12. Andela, N.; Morton, D.C.; Giglio, L.; Chen, Y.; van der Werf, G.R.; Kasibhatla, P.S.; DeFries, R.S.; Collatz, G.J.; Hantson, S.; Kloster, S.; et al. A human-driven decline in global burned area. Science 2017, 356, 1356-1362.

13. Berkey, J.K.; Belote, R.T.; Maher, C.T.; Larson, A.J. Structural diversity and development in active fire regime mixed-conifer forests. For. Ecol. Manag. 2021, 479, 118548.

14. Russo, A.; Gouveia, C.M.; Páscoa, P.; DaCamara, C.C.; Sousa, P.M.; Trigo, R.M. Assessing the role of drought events on wildfires in the Iberian Peninsula. Agric. For. Meteorol. 2017, 237-238, 50-59.

15. Zaitsev, A.S.; Gongalsky, K.B.; Malmström, A.; Persson, T.; Bengtsson, J. Why are forest fires generally neglected in soil fauna research? A mini-review. Appl. Soil Ecol. 2016, 98, 261-271.

16. Doerr, S.H.; Santín, C. Global trends in wildfire and its impacts: Perceptions versus realities in a changing world. Philos. Trans. R. Soc. B Biol. Sci. 2016, 371, 1696.

17. Sannigrahi, S.; Pilla, F.; Basu, B.; Basu, A.S.; Sarkar, K.; Chakraborti, S.; Joshi, P.K.; Zhang, Q.; Wang, Y.; Bhatt, S.; et al. Examining the effects of forest fire on terrestrial carbon emission and ecosystem production in India using remote sensing approaches. Sci. Total Environ. 2020, 725, 138331.

18. Häusler, M.; Nunes, J.P.; Silva, J.M.N.; Keizer, J.J.; Warneke, T.; Pereira, J.M.C. A promising new approach to estimate drought indices for fire danger assessment using remotely sensed data. Agric. For. Meteorol. 2019, 274, 195-209.

19. Hernandez-Leal, P.A.; Arbelo, M.; Gonzalez-Calvo, A. Fire risk assessment using satellite data. Adv. Sp. Res. 2006, 37, 741-746.

20. Chuvieco, E.; Congalton, R.G. Application of remote sensing and geographic information systems to forest fire hazard mapping. Remote Sens. Environ. 1989, 29, 147-159.

21. Gaglio, M.; Aschonitis, V.; Pieretti, L.; Santos, L.; Gissi, E.; Castaldelli, G.; Fano, E.A. Modelling past, present and future Ecosystem Services supply in a protected floodplain under land use and climate changes. Ecol. Modell. 2019, 403, 23-34.

22. Rivas-Martínez, S.; Rivas-Sáenz, S.; Penas-Merino, A. Worldwide bioclimatic classification system. Glob. Geobot. 2011, 1, 1-638.

23. Fernández-Manso, A.; Fernández-Manso, O.; Quintano, C. SENTINEL-2A red-edge spectral indices suitability for discriminating burn severity. Int. J. Appl. Earth Obs. Geoinf. 2016, 50, 170-175.

24. Chrysafis, I.; Mallinis, G.; Tsakiri, M.; Patias, P. Evaluation of single-date and multi-seasonal spatial and spectral information of Sentinel-2 imagery to assess growing stock volume of a Mediterranean forest. Int. J. Appl. Earth Obs. Geoinf. 2019, 77, 1-14.

25. Górriz-Mifsud, E.; Burns, M.; Govigli, V.M. Civil society engaged in wildfires: Mediterranean forest fire volunteer groupings. For. Policy Econ. 2019, 102, 119-129. 